\title{
Polifonía narrativa en la novela histórica D e Santa A nna a la Reforma de Victoriano Salado Álvarez
}

\author{
María G uadalupe Sánchez Robles*
}

Resumen:

Este artículo estudia el discurso de Juan Pérez de la Llana como modelo del Yo narrador y su importancia autobiográfica. El "Yo" que aparece en esta novela se torna más verosímil cuando se observa la presencia de otros narradores como Nicolás Cuevas, Buenaventura O rtiz y Rafael Herrera, que modifican la enunciación del primero. También se puede apreciar cómo los niveles estamentales como la genealogía pueden estar aunados al discurso narrativo para así encontrar el anhelado del poder sociocultural al resaltar características como la nobleza, la riqueza y la fama. Por consiguiente, estos elementos se presentan como parte de los valores sociales y estamentales que están en el trasfondo del discurso narrativo, pero esta visualización de la actuación del narrador y su discurso permitirá validar o sustentar la acciones o hechos que acontecen en torno a la historia como texto autobiográfico e histórico.

Palabras clave:

Novela histórica, historia y autobiografía en la novela, configuración del narrador, narrativa histórica mexicana, Victoriano Salado Álvarez.

* Universidad de Guadalajara. 
Una de las figuras literarias de mayor influencia de la generación de escritores mexicanos que vivieron entre los siglos diecinueve y veinte es sin duda el jalisciense Victoriano Salado Álvarez, quien nació en Teocaltiche en 1867 y murió en la ciudad de México en 1931. Había estudiado leyes en Guadalajara y, como muchos de los hombres de su época, se dedicó a múltiples actividades: fue abogado, maestro, filólogo notable, historiador, escritor, político (llegó a ser subsecretario de Relaciones Exteriores), periodista y Secretario Perpetuo de la Academia Mexicana de la Lengua.

Su capacidad de investigador y sus dotes de artista quedan manifiestos en la novela histórica que publica en dos series. En 1902 aparece D e Santa A nna a la Reforma, serie compuesta por tres volúmenes que incluyen los episodios: "Su Alteza Serenísima", "Memorias de un Polizonte", "El Golpe de Estado", "Los Mártires de Tacubaya” y "La Reforma”. Al año siguiente, en 1903, se publica la segunda serie, intitulada L a Intervención y E I Imperio. Esta segunda serie lleva ya el título general de $\mathrm{E}$ pisodios $\mathrm{N}$ acionales $\mathrm{M}$ ex icanos, misma que la hija del escritor, Anna Salado Álvarez, le dio a la obra en su conjunto cuando la reeditó en 1945.

Explica José Emilio Pacheco que

en sólo cuatro años de su vida, entre los treinta y cinco y los treinta y nueve, Victoriano Salado Álvarez escribió toda su producción novelística que es hasta hoy la obra maestra de la novela histórica en este país. [...] L os E pisodios $\mathrm{N}$ acionales M exicanos se propusieron ser el gran monumento literario erigido al liberalismo reformista cuando se consideraba su culminación y su apoteosis el régimen de Porfirio Díaz. Como Federico Gamboa, Salado Álvarez fue el novelista del porfiriato: al desaparecer la época y el sistema político que conocemos bajo ese nombre, perdió la base que sustentaba su narrativa y lamentablemente no volvió a escribir novelas. (Pacheco, XV) 
$\mathrm{Al}$ analizar la novela D e Santa A nna a la Reforma, primera serie de los E pisodios N acionales Mexiœnos de Victoriano Salado Álvarez, ${ }^{1}$ que se refiere a los acontecimientos nacionales ocurridos entre 1851 y 1861, encontramos la particular presencia de varios narradores, estructura de voces que es dirigida y sistematizada por el narradorprotagonista principal, Juan Pérez de la Llana. Un fenómeno tan peculiar, sobre todo si tomamos en cuenta el proceso elegido como vía de relación novelesca, es decir, el procedimiento textual de la autobiografía - que privilegia por sobre todo al yo individual- debe ser considerado con precisión, dado que aquí estaríamos hablando del funcionamiento conjunto de varios "yo" narradores.

Para acercarnos a esta polifonía, estableceremos, pues, en una primera parte, las características principales de los narradores citados. Esto es, de los protagonistas llamados Juan Pérez de la Llana, Nicolás Cuevas, Buenaventura Ortiz, el cura Rafael Herrera y el "ficticio" Cide Hamete Berengenas. Posteriormente hemos de pasar a los vínculos estructurales que existen entre ellos, es decir, nuestra lectura propuesta como conclusión.

\section{Caractenísticas principales de los narradores}

1. Juan Perez de la L lana. Como característica propia y de su discurso, el narrador fundamental y primordial de la primera serie de los E pisodios $\mathrm{N}$ acionales Mexicanos, Juan Pérez de la Llana, utiliza la manifestación autobiográfica (unas denominadas "Memorias de un veterano") para presentar la relación de sucesos ficticios y reales en la novela.

${ }^{1}$ Para este trabajo sobre los E pisodios N acionales M ex icanos de Victoriano Salado Álvarez, se utilizó la edición facsimiliar de 1902 publicada en 1984 por el Fondo de Cultura Económica, México, en colaboración con el Instituto Nacional de Bellas Artes y el Instituto Cultural Cabañas de Jalisco. En lo sucesivo, las citas textuales, en las que se respeta la ortografía de la primera edición, indicarán únicamente el tomo y las páginas a que pertenecen. 
Este narrador-protagonista es un sujeto profundamente marcado por la noción de la temporalidad. Sobre todo, por el choque de sentidos que sostienen los tiempos presente y pasado. No se trata de una simple relación del paso del tiempo, sino de un enfrentamiento entre un fugaz presente y un extenso pasado. En este sistema, el pasado consistiría en una calidad básicamente desvalorada. Los elementos de dicha calidad son la decadencia, la obsolescencia y el caos, que se acumulan para enfrentarse al presente, el cual hace referencia clara a la fama, la grandeza, y la estabilidad.

Esto es, las referencias textuales sobre el extenso conjunto de hechos y de acontecimientos históricos, de los personajes reales de la literatura y la política de México y de otros países que se conectan con el protagonista y su reflexión sobre el pasado.

En el mínimo presente del narrador se precisa que una de sus máximas intenciones es la de mantener en su texto una ausencia de "compromiso". Pero ésta, formalmente, quedaría conformada por una independencia basada en la autodesvalorización, y la soledad será la base de la libertad promovida como ideal por el protagonista. Aun antes de que conozcamos su nombre, el protagonista-narrador ya se ha encargado de forjarse una imagen, de convocar los signos de un hombre viejo, honesto, solo, supuestamente aliado a la verdad. Más que definir su identidad, el narrador justifica su presencia y se fabrica un ideal, una máscara.

Existe, pues, una problematización del yo, de la identidad. Pese al protagonismo natural que la autobiografía presume, no se conoce el nombre del personaje principal hasta ya avanzados los párrafos. Además, el yo se autocalifica de mediocre y como intelectualmente pobre. Es limitado, y de una exagerada modestia: "Tomé la parte secundaria que era natural me tocara, dados mi corto mérito y mis escasas prendas" (9, I). El yo personal, individual, se ve minimizado frente a los hechos históricos "grandes", los de la Historia con mayúscula.

Cuando por fin devela su nombre, el protagonista lo hace siguiendo la fuerte norma de las reglas sociales: 
Y como es descortesía no hacer saber con quién se trata y con qué derecho se dirige la palabra á las gentes, allá va en otras que no serán muy breves, algo que puede parecer una autobiografía.

Me llamo Juan Pérez, tengo sesenta y nueve años de edad (que cumpliré el próximo veinticuatro de Noviembre, día del bienaventurado Juan de la Cruz). Mis padres, contrariando la sentencia del clásico, fueron pobres y honrados; mi linaje es obscuro, pero de gentes buenas y que nunca dieron que hacer á la justicia.

No puedo ingertar mi árbol genealógico por rama ninguna con la de los siete infantes de Lara ó el Cid Campeador: el primer ascendiente mío que vino á estas tierras se llamaba Pero Pérez de la Llana, era castellano viejo, de tierra de Burgos, y por no sé qué azares de la suerte se alistó en la expedición de Barba; asistió al sitio y toma de México; vino después á la Nueva Galicia en compañía de Guzmán, salió luego con Oñate, ya habilitado como escribano de la expedición, y al fin se asentó como vecino en el pueblo de Tlaxochimaco, situado, como todos lo saben, en la raya de los actuales Estados de Jalisco y Zacatecas. Allí un virrey (creo que Mendoza) lo agració con un sitio de ganado mayor, uno de menor y tres caballerías, "por haber servido á S. M. Con cincuenta pesos en reales y su media annata".

$\mathrm{Ni}$ el españolismo ni la mercedación heredaron los descendientes de Pero Pérez, aunque sí el oficio de escribanos, que ejercieron todos has mi padre. El ranchillo lo enajenó á poco un hijo del agraciado, que se decía Diego; la sangre castellana se convirtió en mestiza, mediante múltiples uniones, legítimas las unas, de la mano izquierda las otras, con criollas é indias. (10, I)

Se presenta aquí mismo una manifestación del pasado que, como habíamos dicho antes, está distanciado diametralmente del presente de la narración. Juan Pérez abandona el estigma de la decadencia 
y la mediocridad para establecer un nexo - mediante la misma fecha de nacimiento, el 24 de noviembre- con una figura de autoridad; nada menos que con el poeta San Juan de la Cruz. El status del protagonista, en contacto con el pasado y con una figura de respeto que lo valida y refuerza, mejora bastante. Su estadio se ve modificado ventajosamente.

Sin embargo, a través de un sistema oscilatorio, el narrador va a confesar posteriormente su total carencia de conexiones con instancias testamentarias (por ejemplo, los Infantes de Lara o el Cid), las cuales resultarán básicas para la formación de su identidad y la instalación de su quehacer, para la evaluación de su oficio. La presencia de la transmisión social testamentaria es considerable: la alcurnia, por ejemplo, se contrapone a la actividad del trabajo llano, al oficio como tal. Y además resultará básica para nuestro personaje narrador (cuyo oficio es el de las letras), porque es exactamente a esa calidad a la que aspira; como ya hemos visto, Juan Pérez de la Llana confiesa su carencia de rasgos nobles, pero al mismo tiempo se inventa una genealogía, o una relación parecida, al establecer un contacto con una figura superlativa del pasado, San Juan de la Cruz.

No será casual la elección de un "antepasado", como el gran místico, para el narrador. Al asimilarlo, Juan Pérez obtiene una doble ventaja: forja su genealogía, y también valida su oficio, el de escritor, con un efecto reforzado que integra lo testamentario y el trabajo llano.

Es de tomar en cuenta en el sistema de la primera serie de los E pisodios $\mathrm{N}$ acionales Mexicanos la construcción de los nombres, sobre todo el del narrador principal, Juan Pérez de la Llana, en el que distinguimos una formación doble. Por una parte, los elementos "Juan Pérez" forman una unidad. En nuestro país, este nombre equivale, dada la popularidad y la frecuencia, a la denominación de un sinnúmero de personas. Por tanto, sería el nombre de cualquiera, de un miembro más de la masa. Por el contrario, la segunda parte del nombre, el elemento compuesto por "D e la Llana", hace la referencia opuesta; establece una posición ligada a un origen y a unas relaciones de mayor nivel social. Hay que añadir la semejanza que exis- 
te, funcionalmente, entre el "De la Llana" y el "De la Cruz", del poeta que valida la existencia literario-social del narrador protagonista. Tenemos aquí, la presencia de una hibridación social y denominativa, que nos dirige, de nuevo, hacia una acendrada búsqueda de la identidad. Hay una constante significativa que consiste en utilizar ciertos elementos del nombre de Pérez, dependiendo de la situación en la que el personaje se encuentre. En ocasiones relevantes para la instancia narrativa, se presenta más el segundo apellido: el de renombre; cuando el contexto o la situación relatada cambian, cuando no resultan tan valoradas, se presenta más el primero de los apellidos. La identidad de Pérez de la Llana se bifurca para adecuarse a la situación social o histórica en la cual se encuentre.

La novela de Salado Álvarez suele fluctuar entre la convocatoria de ciertas formas y la consiguiente ruptura con ellas mismas. Para encontrar la identidad, el narrador-protagonista, como ya hemos visto, frecuenta las genealogías, ya sean inventadas o propias de la "realidad" del relato. Es necesario que nos detengamos en la manera en la cual Pérez de la Llana describe a su "familia" -institución fundadora y figura del pasado- en la novela. D esde la familia, se establece un fuerte vínculo entre la actividad literaria y la cuestión sanguínea; entre el oficio y la transmisión. Se instala un sistema sucesorio que tiene que ver más con el trabajo que con la calidad social del individuo. Sin embargo, la actividad no sustituye a la nobleza, sino que se emparenta con ella, se vuelve un equivalente. En este universo novelesco, para existir es necesario tener una genealogía que sostenga al individuo.

La familia del narrador se divide en dos partes: la primera, formada por el padre y la segunda por las mujeres (madre y hermanas de Juan Pérez), apenas mencionadas y en situación de desvalorización total. Así cuenta quiénes fueron sus hermanas:

Petra, que casó el 54 con el Coronel Avalos; Manuela, mujer de Naranjo, el riquísimo denunciante de bienes nacionalizados; Rudesinda, que vive soltera y convertida en rata de iglesia; Catalina, preciosa criatura que murió antes de llegar á la edad 
núbil; Toribia, cuya triste historia contaré quizás algún día, y yo, que fui el último vástago de la familia y el único varón en ella.

No puedo decir que haya nacido con pie derecho; cuando tenía unos pocos meses; mi madre, que pertenecía á la familia de los Osorios, de Juchipila, murió del cólera en 1833, y me dejó entregado en manos de tías, de nanas y de chichiguas que me hicieron perder la salud y me ennegrecieron el humor. (12. I)

El narrador llega hasta la descripción de la figura paterna: "Mi padre, que se llamaba don Andrés (D ios lo tenga en su gloria), era la persona más perfecta y cabal que haya visto jamás" (12, I). Entre Pérez y su padre hay una diferencia en el tratamiento. Una muestra del discurso de las costumbres y reglas sociales del respeto y la honra; el calificativo de "don" (equivalente a "Señor") jerarquiza la relación, no mantiene solamente la cuestión temporal. El desbordamiento cualitativo, el exceso en la calificación del padre, refuerza la noción de enfrentamiento entre lo que es muy valorado y lo que no lo es. Formaliza sólidamente un profundo compromiso con las figuras de autoridad. Este sistema de lo valorado versus lo desvalorado tiene una manifestación en el mismo padre del protagonista: se menciona que, pese a todas sus cualidades y perfecciones, "no tuvo más defecto que su grande e incorregible pobreza", (12, I). Dicha pobreza es considerada textualmente, pues, como negativa. Se le coloca en el espectro de lo inferior, de lo desvalorado.

La voz narrativa primordial funda una supremacía total sobre lo narrado. Como es una práctica autobiográfica la que se ejerce, necesariamente todos los hechos pasan por el tamiz del yo. Existe una mirada vigilante y definitoria de Juan Pérez sobre los acontecimientos que atestigua y relata. Antes mencionábamos que la vocación literaria era una heredad propia de la familia Pérez; que se transmite, como otros transmiten los títulos nobiliarios. Juan Pérez de la Llana ratifica la labor literaria de sus antepasados.

El sistema de transmisión, en este caso de un oficio, adquiere las características de legado de cualidades testamentarias. Encontra- 
mos una carga suficiente de intención de validar socialmente una posición y una circunstancia. Existe también el choque de sentidos, pues si por una parte se promueve la equivalencia entre los niveles de oficio y de nobleza, por otra parte (nueva oscilación) se asegura textualmente en un alarde determinista que la herencia social es equiparable a la herencia de los animales, la biológica: "Pero no podía ser de otro modo; como desciendes de esta familia en que se ha heredado la habilidad por línea recta de varón [... ] bendito sea Dios; de casta le viene al galgo ser rabilargo".

Al comparar y volver equivalentes a las herencias social y biológica, el texto se permite validar, hacer justa la herencia del oficio (del trabajo). En los dos casos tenemos dos elementos que en principio se contraponen. Pero gracias al sistema de comparaciones, la herencia social y de oficio es tan "legítima" como la herencia de la sangre (nobleza) o biológica. Pérez puede acceder así a un nivel más valorado, superior, consistente en todo aquello que no le pertenece de inicio. Todo el "problema" viene del antiguo desprecio que los nobles medievales tenían por el trabajo físico y su consiguiente desprestigio a los ojos de los miembros de una sociedad testamentaria. D e lo que se trata aquí, es de la búsqueda de validación y de ascenso social de un miembro de nivel considerado "inferior", en este caso representado por Pérez de la Llana.

El valor es un concepto sumamente importante en la figura del narrador-protagonista. Los valores de Juan Pérez de la Llana serán esenciales para comprender su propio funcionamiento. En él persisten valores como el "honor", cuya continuidad es inquebrantable. Se enfrenta, como concepto a las expectativas - propias y ajenas- de poder y ascenso social. Sin embargo, el honor permanece inamovible como parte del conjunto de signos, de cualidades, que validan al personaje. En Pérez de la Llana existe una gran tendencia a sujetarse a modelos de comportamiento o normas sociales. Y es frecuente que esto lo lleve a rechazar ciertas prácticas que resultan ajenas a su "compromiso" con el honor. Cito: 
Buscaba el combate leal, caballeroso y honrado, y se me ofrece el asesinato de encrucijada, el asalto de bellacos, en medio de la sombra y la traición. No puedo acompañarles a ustedes. Pero si es lo que se acostumbra en estos casos, pues yo no acepto esas costumbres. (108, II)

El código moral de este narrador es complejo, pues no se estabiliza en sólo unos cuantos puntos. Una de sus preocupaciones recurrentes es la de tratar de definir su propia obra, su práctica literaria. La indefinición que de esta preocupación se desprende se constituye por el enfrentamiento de las nociones de "verdadero" y "falso". Hay una obsesiva preocupación por enfatizar la cualidad de "verdadero" de la relación de lo histórico y su narración. En el capítulo XXVI se presenta una nota que cita: "Los diálogos que siguen son auténticos" (267, II). La consistencia del honor tiene que ver, indisolublemente, con la cantidad de información "verdadera" que se ofrezca en el texto. El honor se une a la autenticidad para dar lugar a una concreción de las ideas manejadas textualmente en los E pisodios $\mathrm{N}$ acionales. $\mathrm{Y}$ más que definir su obra, que se sigue manteniendo en una zona de hibridación, no muy esclarecida, lo que se logra establecer son los basamentos de la posición ideológica textual.

No puede resultar ajeno el hecho de que no sea suficiente la instauración y el desenvolvimiento de la voz imperativa de Pérez de la Llana en la narración. La ruptura de la homogeneidad se muestra en la forma de convocatoria que abre el espacio de la diégesis a nuevos y secundarios narradores. Vendrán tres nuevas voces que desbordan - una vez más- la forma de la autobiografía, recurso que se instala perfectamente en el conflicto entre lo individual y el conjunto. En una obra pretendidamente autobiográfica (relevancia del yo y de su relato) encontramos la suma de otras tres "autobiografías".

A continuación, las principales características de los otros representantes de la polofonía diegética.

2. N icolás Cuevas. Cuando Nicolás Cuevas aparece, es de inmediato estigmatizado por Pérez de la Llana. Lo compara con el Periquillo 
Sarniento: "Covarrubias se quedó parado y al fin, juzgando al Periquillo aquél un tramposo de los que se valían de sorpresas para robar o pegar chascos, lo rechazó con buenos modos" (164, I). Al convocar en la novela a una figura tan representativa, no sólo se establece una conexión intertextual; a la vez la referencia literaria conlleva la concesión y el apoyo de una autoridad, un escritor y una obra, ambos afamados ya.

La figura de Cuevas conserva muchas de las características que definen a Pérez de la Llana. A Cuevas se le otorga la voz narrativa y además se le proporciona un apartado exclusivamente redactado y firmado por él. Sus "Memorias de un polizonte" se insertan (discontinuidad y ruptura) en las "Memorias de un veterano", en aras de una pretendida perspectiva diferenciadora en relación con los hechos históricos narrados.

Estas nuevas memorias contienen muchos paralelismos con las que firma Pérez de la Llana. Sin embargo, a Cuevas se le define de manera más desvalorada, con el término de "polizonte", ya que su profesión, en principio y por la mediación de su coterráneo Pérez de la Llana, es la de un policía al servicio del presidente y dictador Santa Anna. Cuevas funcionaría como una especie de figura contrapuesta, enfrentada a Pérez. Las memorias de Cuevas contienen de manera más explícita los objetivos que persigue su "autor", aunque sin abandonar ese tono de modestia que lo equipara con su antagonista narrador.

Son tres los elementos que marcan diferencias entre estos dos narradores. El primero se presenta mediante una ausencia: la de los orígenes del personaje. No se conoce nada sobre la familia de Cuevas y este vacío lo ocupa el conjunto de personajes que él mismo convoca, a diferencia de Pérez, que tiene un pasado familiar que en mucho lo define. Cuevas además sigue el ejemplo -el paradigmade dicho conjunto. Este grupo de personajes es definido por Pérez como "insignes desocupados" (224, I). Entre las diferencias de los narradores se encuentran los objetivos concretos de cada uno. Cuevas abandona el tono de falsa modestia que recorre el discurso de Pérez y se cree ya merecedor de "un asiento modesto de galería de 
cazuela en esa famosa y codiciada inmortalidad" (224, I). Ésta es una búsqueda que está muy asociada a las expectativas de un literato, historiador, o científico.

La influencia en la formación del personaje por medio del Periquillo es considerable. Hay que acotar que la pretendida fama funciona solamente como un medio para alcanzar un objetivo más alto, proritario y urgente: la búsqueda, reconstitución y confirmación - por parte de un investigador académico- de sus orígenes (españoles).

Y quién sabe si en fuerza de las cosas que yo revele [...] venga algún investigador y revolviendo papeles [...] reconstruya mi biografía y demuestre que soy descendiente de algún conquistador anónimo o de alguna azafata o camarista de la corte de nuestros católicos y por desgracia olvidados reyes. $(225, \mathrm{I})$

Esta preocupación se implanta de manera absoluta en el discurso y objetivos del personaje, de una manera curiosa ya presentada arriba: vuelve híbrida la presencia de los discursos del mérito y de la transmisión sanguínea. De lo que se trata, a fin de cuentas, no es de una búsqueda de la verdad, sino de una búsqueda definitiva de validación a través de una verdad pretendida. No es necesario que sea cierta, sino que el historiador, el reconstructor de la relación de hechos, lo pruebe y lo demuestre. Para validar las expectativas de ascenso y reconocimiento, el camino es el de la siempre pretendida "verdad". Ella se instala en el discurso de Cuevas y se confirma como el gran signo que objetiviza al relato. Esta búsqueda aparece como el valor de un orden más codiciado por los narradores.

La figura de Cuevas, con rasgos propios de la picaresca, cambia radicalmente en el transcurso de la narración. El signo del cambio constante y obsesivo es la marca del personaje. De ser simpatizante de Santa Anna, pasará luego al bando contrario, y mudará de ideas y aspecto. Se localizan signos pertinentes al ascenso social y a la apariencia; al desbordamiento cuantitativo; al conflicto entre lo falso 
y lo verdadero y al estado de confusión. (Por ejemplo: “¿No sigues en la policía? [...] Eso se acabó hace mucho tiempo; ahora me dedico al comercio [...] presto sobre alhajas y ropas en buen uso... La política... que se ocupe de ella quien no tenga en que caerse muerto" (147, II). Nicolás Cuevas encarna de manera preponderante en el relato, la figura del ascenso. Y si Pérez de la Llana establece lazos de sentido con el poeta San Juan de la Cruz, Cuevas lo hace con una figura política mexicana de la época: el general Porfirio Díaz. En ambos se manifiesta esa recurrencia a valorar un discurso y un orden jerárquicos y de legación, de herencia (cuando no es el mérito de proseguir la labor familiar, es el de mantener una ideología).

3. Buenaventura 0rtiz. La inserción de un nuevo personaje narrador, Buenaventura O rtiz, privilegia también el recurso de la autobiografía que mediatiza a la novela, formalizándose, como en el caso de Cuevas, en la escrituración de unas "memorias". Este nuevo desdoblamiento de la instancia narrativa se ve definido con la inserción de un calificativo que, como parte activa de los paratextos, marca una tendencia y prelectura de lo que se va a narrar: mocho. "Mocho" es el apodo insultante que los liberales mexicanos dieron a todo aquel miembro del bando conservador; recalca el carácter incompleto y retrógrado de la facción conservadora. Ésta será la perspectiva general que acompañará al nuevo narrador. Las "Memorias de un mocho" destacan por su brevedad en cuanto a espacio narrativo y tiempo narrado. La época a la cual se hace referencia está comprendida entre 1859-1860. El desbordamiento cuantitativo no está presente aquí.

La denominación del narrador y protagonista parte -como en el caso de Cuevas- de una visión negativa del narrador principal, Pérez de la Llana, la cual es sumamente frecuente. Pérez ejerce una suerte de control, de supremacía sobre los otros, pues los define y los coloca en la zona inferior de su escala de valores. En cuanto a Buenaventura Ortiz, la usurpación, la desvalorización de su presencia es aún más marcada. Las palabras de Pérez invaden el espacio de apertura del capítulo que corresponde a O rtiz. Cito: 
Si buscas, lector discreto, noticias de la vida y obras del autor cuyas hazañas se cuentan en este lugar, en cualquier Larousse, Vaprau 0 Gubernatis de vieja o cercana data, perderás tu tiempo y tu trabajo, porque en ninguna enciclopedia ni diccionario se hace mención del historiador Buenaventura Ortiz. (109, III)

Su presencia obedece a la creación o reforzamiento de un sistema que va de la inexistencia (la nada, el vacío) a la existencia (la presencia, el reconocimiento, la memoria), siempre avalada por la confirmación de alguna autoridad; en este caso se trata de la presencia editorial de renombre, sobre todo extranjera. La sujeción y la relación de dependencia se funda entonces en procesos de desvalorización y complementariedad. La primera es reiterativa, y aunque el espacio que ocupan las palabras de Pérez de la Llana es mínimo, en su alocución se encuentran dos minimizaciones: una es el empleo del diminutivo "Venturita", y la otra la frase "pero consiste todo en que la forma [literaria] de mi pobre amigo era más mala aún que la mía, y queriendo enmendar esto y lo otro, rehice todo lo escrito" (11, III). Si se suman los signos consignados a la instauración de un respeto y una deferencia hacia figuras masculinas de autoridad, el paternalismo que se transmite es implacable.

La mencionada complementariedad entre Pérez y los personajes-narradores que convoca en la novela se inscribe, como signo, en la constante textual de una búsqueda de totalización. Ortiz funciona como una especie de contrapeso político a la posición "liberal" de Pérez. El personaje principal, sin embargo, no ostenta una definición unívoca en su postura política, ya que ésta es significativamente aleatoria. La supuesta impresión de equilibrio que se busca al presentar diferentes visiones del relato histórico-literario no es tal, sino más bien una manera de enfrentar a la otredad de una forma siempre prejuiciada (las desvalorizaciones del primer narrador hacia los otros, sus conflictos, etc.).

La irrupción decidida de Pérez de la Llana en el discurso de Buenaventura O rtiz culmina con la autovalidación de su quehacer 
literario. El valor estético de "Memorias de un Mocho" se origina de manera unilateral en el propio Pérez, negándole todo mérito al personaje activo y pretendidamente principal y 'Iocutor' de este nuevo testimonio. Las "Memorias de un Mocho" funcionan como una oportunidad para demostrar sus propias virtudes creativas, desvalorizando desde el principio el aspecto "histórico" de lo narrado. El concepto de historia aparece como sujeto de segundo orden y cuyo sustento es el subjetivo testimonio de la anécdota.

"Memorias de un Mocho" es, a su vez, texto portador del discurso de Cide Hamete Berengenas, que firma la parodia "El ingenioso hidalgo don Quijote de la garra."

D e Santa A nna a la Reforma es definida como una autobiografía (ficticia) que escribe Victoriano Salado Álvarez. El protagonista, el supuesto escritor directo del libro, es Juan Pérez de la Llana, quien se multiplica para otorgar voz a Nicolás Cuevas, el cura Herrera y a Buenaventura Ortiz; este último convoca otra presencia de la que no es posible saber más que la referencia literaria, en dos partes, una la intertextual (es como el Cide Hamete Benengeli, del Q uijote de Cervantes, a quien éste atribuye la redacción en árabe del célebre libro), y la otra, la huella de su "escritura" en su novela. En esta proliferación de desdoblamientos parecería que el signo de la definición fuese perdiendo, con cada recurrencia de una presencia narrativa, su fuerza y su denominación, para dar lugar a la indefinición.

4. Rafael $\mathrm{H}$ errera. Existe en el texto una pluralidad que se encuentra más en el orden del efectismo que en el de una realidad convocada por la ficción. El tercer narrador es presentado directamente por Pérez de la Llana, y se trata del cura Rafael Herrera. El cura Herrera también es blanco de la burla y el menosprecio de Pérez de la Llana. Este último lo define casi como un ser grotesco: "Era Herrera un mestizo nervioso; de pocas carnes y menos entendimiento" (211, III). D e este nuevo narrador, es posible abstraer funciones concretas. Una, cuyajustificación es imprescindible por tratarse de un personaje que cubre la ausencia de Pérez de la Llana en su pueblo, lleva al 
lector a conocer esos pasajes de la historia porque Pérez no es capaz de narrarlos. En el discurso de este último existe una recurrencia por describir situaciones y personajes con el apoyo de signos y estructuraciones que remiten a un discurso absolutista y totalizador. Con expresiones como "todo" y "nada" se logra un efecto de globalización y generalización total, ya negativa, ya positiva.

La presencia del cura Herrera es un signo a nivel narrativo que confirma esa tendencia totalitaria: el hecho de que se le entregue la voz a este personaje-narrador para que el lector esté al tanto de los acontecimientos sucedidos durante la ausencia de Pérez en su pueblo natal, manifiesta esa ansia de globalización, ese afán de cubrirlo todo, de reescribirlo todo sin dejar un cabo suelto. La "mirada" de Pérez se vuelve escudriñadora, sigilosa, capaz de sacrificar su propia presencia en aras del control de escribir y vigilar, inventar y manipular. En el discurso de la novela, el acontecimiento histórico se rodea de un ambiente de claras luchas por apropiarse de la "verdad" de los hechos, en una atmósfera de negación e intolerancia hacia el trabajo o consideraciones de los otros. Pérez cierra la exposición de su postura hacia un historiador llamado Azafrán, citando unas minucias de precisiones temporales para descalificar al otro como historiador: "la famosa batalla de las Guásimas [ ... ] fue el trece [de febrero] a las doce de la noche" en lugar de "el día catorce de febrero" (268, III). D esde la formación de este tipo de discursos, la intolerancia aparece como signo fundador de una problemática hacia la comprensión de la otredad.

La presencia de Herrera cumple dos funciones, la primera, ya consignada, consiste en narrar los acontecimientos en la ausencia del narrador-protagonista principal. La segunda, puede articularse como una respuesta a una necesidad textual de consolidar el discurso de lo valorado y lo superior. Herrera es incluido en los E pisodios para que pueda narrar (modestia obliga) un pasaje en que se manifiesta el heroísmo de Pérez de la Llana: "aquí dejo la palabra al señor cura Herrera, que con su inapreciable libro, L as nuevas décadas de $\mathrm{H}$ errera, una relación de los sucesos notables que han acontecido en la villa de Tlaxochimaco, refiere todo con sus puntos y comas y 
me evita el bochorno de alabarme" (311, III). Hay que poner de relieve el aspecto siguiente: el primero se relaciona con el liderazgo que describe el accionar de Pérez. Si ya antes se había mencionado que existe un conflicto muy marcado entre las nociones de individuo y de comunidad o conjunto, y que se excluyen mutuamente, se encuentra que la relación entre el grupo y el individuo se va a modificar. El liderazgo de Pérez relatado por Herrera se constituye en un matiz del conflicto entre el individuo y la colectividad.

\section{Vínculos estructurales: condusión}

D entro del encabalgamiento de autobiografías que es el texto de la novela D e Santa A nna a la Reforma, primera serie de los E pisodios $\mathrm{N}$ acionales $\mathrm{M}$ ex icanos, encontramos, pues, la presencia preponderante del "yo". Pero se trata de un "yo" continuamente desvalorado y colocado en una instancia calificada por el mismo texto como inferior. Cada vez que las entidades subjetivas de las voces narrativas son presentadas, aparece la sistemática de la falsa modestia, del calificativo minimizador o de una serie de procesos desvalorizadores.

Este mismo "yo" acendrado en el que podemos reducir a los narradores-protagonistas-testigos es una subjetividad que confiesa (y podríamos decir, lamenta) su carencia de nexos con figuras de un estrato testamentario. La nobleza, la riqueza y la fama son el nivel deseado, la posición a alcanzar a lo largo de la novela. Y una zona que por su misma opacidad va a aportar una posibilidad de ascenso será el pasado, puesto que lo que los pretendidos historiadores 0 relatores de las diferentes partes de la obra realizan no es dar luz en distintos hechos o temas a discusión, sino aprovecharse de su posibilidad de relatar, reescribir la historia para crearse una genealogía ad hoc que valide y justifique su anhelo de ascenso y superioridad.

Gracias a que aquí se considera como de primer orden el tener una genealogía que pueda sustentar y validar la existencia y la labor del "yo", dicha carencia mencionada arriba problematizará la identidad y las posibilidades de ascenso. Por ello es necesario acudir al 
género histórico a la vez que al autobiográfico. No para dar una idea clara de la manifestación práctica de cada uno de estos géneros, sino para, mediante una hibridación, poder fabricar un sentido, una instancia que pueda servir a la intención de hacer equivaler la herencia biológica a la herencia del mérito o del trabajo (los narradores refuerzan este último aspecto convocando una instancia poderosa: la herencia literaria, San Juan de la Cruz, Cervantes, que traen a cuenta a la menor provocación para hablar de su oficio y de sus perspectivas).

El resultado de la suma de "honor" más "autenticidad" no podrá ser puesto en duda ni siquiera por los detentadores originales de un estrato social o económico. Se fabrica la verdad. Se vuelve artificial en el texto. Y como los narradores resultan ser testigos privilegiados pero forzosos y forzados (hay que ver su prodigioso don de ubicuidad, para estar precisamente donde ocurre lo importante, lo grandioso, lo histórico), esta capacidad de mediación les facilita la capacidad de reconversión de la historia, según sus necesidades. Así lo apreciamos en la enorme carga de subjetividad que portan sus relaciones supuestamente históricas.

Sus mediaciones están comprometidas desde el principio con las figuras de autoridad - definidas o no- para emularlas e identificarse con ellas; para satisfacer y validar un ansia de ascenso social; rastreamos en la participación de los narradores la consolidación de las supremacías, el establecimiento (o la búsqueda de establecimiento) de la jerarquía. No sólo en el respeto y en la deferencia que les muestran los personajes y los narradores, sino también en las declaradas invasiones del espacio escritural del otro (las memorias incluidas dentro de las memorias, Pérez en el texto de Ortiz, el editor en el texto de Salado/ Pérez). Existe también otra supremacía que a través del análisis se nos vuelve clara; la supremacía de la anécdota subjetiva sobre la información pretendidamente histórica. La participación de los narradores en el texto es una reseña y una reivindicación de su individualidad particular.

Privilegian su propia circunstancia sobre los pasajes históricos, intercalando ambos elementos. En resumen, es el individuo desva- 
lorizado, no necesariamente "democrático" y contemporáneo el que se enfrenta a la supremacía política, económica o social; sino el ser inferiorizado que aspira a reproducir un sistema totalitario y vertical; no a confrontarlo.

\section{Bibliografía}

Avellaneda, Andrés. El habla de la ideología. Buenos Aires: Sudamericana,1983.

Barthes, Roland et al. A nálisis estructural del relato. México: Premiá, 1982.

Blancarte, Roberto. Cultura e identidad nacional. México: Fondo de Cultura Económica, 1994.

Cardoso, Ciro (coord.). M éxion en el siglo X IX (1821-1910). México: Nueva Imagen, 1982.

Cros, Edmond. D el'engendrement des formes. Montpellier : CERS, 1990. 1980. Ideología y genética tex tual, el caso del Buscón. México: Planeta, . L ecture ideologique du L azarillo de Tormes. Montpellier: CERS, 1984.

Pacheco, José Emilio, "Presentación”. L a novela histórica y de folletín. Clásicos de la L iteratura Mexicana. Comp. José Emilio Pacheco. México: Promexa, 1990.

Salado Álvarez, Victoriano. D e Santa A nna a la Reforma. M emorias de un veterano, en $\mathrm{E}$ pisodios $\mathrm{N}$ acionales $\mathrm{M}$ exicanos, edición facsimilar de la de 1902. México: Fondo de Cultura Económica, 1984. 